Voix et Images

volxetimages

\title{
Michel van Schendel et l'invention des formes
}

Jacques Allard

Volume 11, numéro 2 (32), hiver 1986

Michel van Schendel

URI : https://id.erudit.org/iderudit/200552ar

DOI : https://doi.org/10.7202/200552ar

Aller au sommaire du numéro

\section{Éditeur(s)}

Université du Québec à Montréal

\section{ISSN}

0318-9201 (imprimé)

1705-933X (numérique)

Découvrir la revue

\section{Citer cet article}

Allard, J. (1986). Michel van Schendel et l'invention des formes. Voix et Images, 11(2), 165-166. https://doi.org/10.7202/200552ar d'utilisation que vous pouvez consulter en ligne.

https://apropos.erudit.org/fr/usagers/politique-dutilisation/ 


\title{
Michel van Schendel et l'invention des formes
}

\author{
par Jacques Allard, Université du Québec à Montréal
}

Il se présente comme un métèque. Il revendique la métécité comme la condition même de l'écrivain et de son écriture. Il déclare vivre l'étrangeté qui transforme. Né en France de parents belges, Michel van Schendel est un Québécois de trente-trois ans. Arrivé ici à l'âge de vingt-trois, sur un coup de tête qui était un appel du cœur. Avec sa formation en droit et en sciences économiques, il fera tous les métiers de la survie dans le Québec duplessiste. Lui, militant communiste de Paris. Pour en venir à s'affirmer finalement dans le seul titre qui compte vraiment, qui coiffe tous les autres, celui de l'écrivain. Comme l'ont voulu ses pairs en lui octroyant le Prix du Gouverneur général en 1981, alors qu'il n'était pas encore reconnu comme simple citoyen... On s'empressera alors de lui conférer ce sous-titre nationalcanadien qu'il avait réclamé depuis plus de vingt ans. Pouvoir de l'écriture. Une autre histoire de "migrant» dans feu "les pays d'en haut" (voir notre dossier précédent consacré à Naïm Kattan).

Comme on sait ou comme on l'apprendra un peu par ce qui suit, Michel van Schendel aura été - ce n'est pas un hasard - dans tous les lieux et laboratoires de la modernisation récente de notre société. Journaux marginaux ou grande diffusion (l'Autorité du peuple, le Nouveau journal, La Presse). Revues de la lutte sociale et politique (Cité libre, Parti pris, Socialisme). Écrivant de l'économique, du politique, du culturel. Critique d'art et de littérature. Grandes et petites maisons d'enseignement ou de production culturelle, du Collège Valéry à l'Université du Québec à Montréal en passant par Radio-Canada et l'Université de Montréal. Enseignant, scripteur. Toujours : écrivain, même quand il ne publie pas. Avant sa première manifestation publique dans le recueil collectif la Poésie et nous, réunissant les communications de la première des Rencontres de la revue Liberté (1957).

Ce praticien de la métécité se déclare aussi un organisateur de formes. Il est un adepte de la "trans-forme". Et un écrivain de l'amitié, d'où l'invention généreuse de sa parole comme on le verra dans l'entretien qu'il nous a donné le printemps dernier, au bout d'une année difficile. La direction de la revue aura pu cette fois répondre à cette générosité: i.e. augmenter les pages habituelles du dossier, sans toutefois permettre la reproduction entière de l'entrevue. (Pour les intéressés, la partie la plus consistante du non publié a trait à la sémiotique [non-greimassienne] que propose notre invité. Pour lui, La sémiotique a pour fonction d'analyser ce qui, dans l'idéologique, correspond à une matière formelle... l'idéologique au plan de sa pragmatique jusque dans l'analyse de l'avènement des formes. Il essaie, dit-il, de reconstituer à 
l'intérieur de la réflexion sémiotique le travail qui aurait pu être poursuivi par des marxistes, si des marxistes s'étaient donné la peine de réfléchir sérieusement au poids de l'idéologique. Et la socio-sémiotique serait au fond ce qui, dans l'idéologique concerne ce [qu'il] appelle [lui] "l'instituant" et "l'institué», c'est-à-dire le fragment discursif, forme matérielle de l'idéologique... . Il va de soi que ce collage de quelques citations ne constitue pas autre chose qu'une indication de la direction des propos de M. van Schendel).

Ce dossier exceptionnel comprend aussi deux études attentives consacrées à la poésie de notre auteur, par André Brochu et Chantal de Grandpré. On trouvera ensuite la contribution éclairante de Joseph Melançon sur «le tracé d'un parcours critique». Et finalement une riche bibliographie, signée Roger Chamberland et Pascale Noizet. Sans oublier les "Seize distances pour le doigt, l'ouvert, la page", poème inédit de Michel van Schendel qui ouvrait notre dossier. 